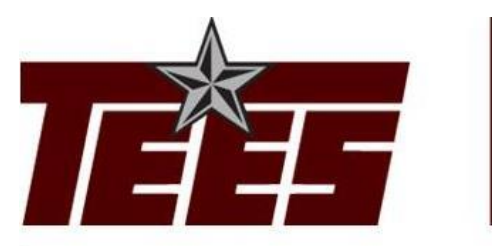

MARY KAY O'CONNOR PROCESS SAFETY CENTER

TEXAS A\&M ENGINEERING EXPERIMENT STATION

$19^{\text {th }}$ Annual International Symposium

October 25-27, 2016 • College Station, Texas

\title{
Large-Scale Vented Deflagration Tests
}

\author{
Peter A. Diakow, J. Kelly Thomas and Philip J. Parsons \\ Baker Engineering and Risk Consultants, Inc. ${ }^{\circledR}$ \\ 3330 Oakwell Court, Suite 100 \\ San Antonio, TX 78218-3024 \\ (210) 824-5960 \\ pdiakow@BakerRisk.com
}

\begin{abstract}
This paper presents results from a test program carried out to determine the peak deflagration pressure achieved within a congested enclosure vented through one wall of the enclosure. The industry standard in the United States for predicting the peak pressure developed in a vented deflagration is the National Fire Protection Association's Standard on Explosion Protection by Deflagration Venting (NFPA 68). The NFPA 68 (2013 edition) vent area correlation accounts for varying degrees of congestion if the ratio of the obstacle surface area (Aobs) to that of the enclosure $\left(A_{s}\right)$ is greater than 0.4 (i.e., $\left.A_{r}=A_{o b s} / A_{s}>0.4\right)$. The tests described in this paper were performed using an obstacle array with an $\mathrm{A}_{\mathrm{r}}$ ratio of less than 0.4 .

These tests were conducted in a rig with a 48-foot width, 24-foot depth, and 12-foot height. The rig was enclosed with solid walls, roof, and floor, allowing for venting through one of the long walls (i.e., 48-foot by 12-foot). The venting face of the rig was sealed with a 6 mil $(0.15 \mathrm{~mm})$ thick plastic vapor barrier to allow for the formation of a near-stoichiometric propane-air mixture. The flammable gas cloud was ignited near the center of the rear wall. Steel vent panels (20-gauge, $2 \mathrm{lbm} / \mathrm{ft}^{2}$ ) were installed over the plastic vapor barrier using explosion relief fasteners. The vent panels were configured to release at 0.3 psig; vent panel restraint devices were not utilized. The congestion inside the rig was provided by a regular array of vertical cylinders (2-inch schedule 40 pipe and 2-inch outer diameter cylinders) giving area and volume blockage ratios (ABR and VBR) of $4.9 \%$ and $2.2 \%$, respectively, within the congestion array. The obstacle to enclosure surface area ratio $\left(A_{r}\right)$ for this obstacle array pattern is 0.3 with the array extended throughout the rig, which is less than the critical value to account for congestion in the NFPA 68 correlation.
\end{abstract}

Four series of tests were conducted with varying vent parameters, flammable gas cloud sizes, and congestion levels. Baseline tests were performed with the congestion array and flammable gas cloud extending throughout the rig without vent panels present (i.e., vapor barrier only). The 
second test series included the addition of vent panels for the same congestion pattern as that employed for the baseline tests. The third test series utilized a flammable gas cloud which filled only the back half of the rig. For the fourth test series, the congestion array only occupied $1 / 4$ of the rig. The peak pressures and impulses for each test series are provided, along with pressure histories internal and external to the rig for selected tests. The steel vent panel throw distance is also provided as a function of internal peak pressure.

The test data were compared with the predictions of the vent area correlations provided in NFPA 68. For all but the fourth test series (i.e., congestion array occupying $1 / 4$ of the rig), the average internal peak pressures were approximately a factor of 2 larger than those predicted by NFPA 68 .

\section{Introduction}

The primary objective of these tests was to measure the blast loads produced by a vapor cloud explosion (VCE) within a vented congested enclosure and compare the measured peak pressures to those based on the industry standard for predicting vented deflagration peak pressure (i.e., NFPA 68, 2013 Edition). Data was also collected regarding external blast wave propagation and panel throw distance. Twelve tests (three tests for each of four test series) were performed in this test program. The test matrix is provided as Table 1.

Table 1: Large Scale Vented Deflagration Test Matrix

\begin{tabular}{|c|c|c|c|c|}
\hline Test Series & Description & $\begin{array}{c}\text { Flammable } \\
\text { Volume }\end{array}$ & $\begin{array}{c}\text { Congested } \\
\text { Volume }\end{array}$ & Vent Parameters \\
\hline A & Baseline & $100 \%$ & $100 \%$ & 6 mil plastic \\
\hline B & Vent Panels & $100 \%$ & $100 \%$ & 20 gauge steel panels \\
\hline C & $50 \%$ Cloud & $50 \%$ & $100 \%$ & 20 gauge steel panels \\
\hline D & $25 \%$ Congested & $100 \%$ & $25 \%$ & 6 mil plastic \\
\hline
\end{tabular}

\section{Test Rig Configuration}

The test rig was an enclosure with three solid walls, roof and floor with dimensions of 48 feet wide, 24 feet deep, and 12 feet tall. Venting was allowed through one of the long walls (i.e., 48-foot by 12-foot). The venting face of the rig was sealed with a 6 mil thick plastic vapor barrier, which released (i.e., tore open) at approximately $0.1 \mathrm{psig}$. For test series $\mathrm{C}$, the plastic vapor barrier was installed halfway between the rear of the test rig and the venting surface. This allowed for the formation of a fuel-air mixture only in the rear half of the enclosure. For all other test series (A, B, and D), the vapor barrier was installed on the external venting face of the rig, resulting in a flammable cloud filling the entire enclosure volume.

A near-stoichiometric (slightly fuel-rich) propane-air mixture was produced inside the test rig for all tests and was ignited in the center of the rear wall, opposite the venting surface. For test series B and C, steel vent panels (20 gauge) were installed over the plastic vapor barrier using Fabco ${ }^{\circledR}$ Vent-All explosion relief fasteners to provide a 0.3 psig vent release pressure $\left(\mathrm{P}_{\text {stat }}\right)$. The vent panels weighed $2 \mathrm{lb} / \mathrm{ft}^{2}$. Vent panel restraint devices were not utilized. Figure 1 shows photos of the test rig configured for test series $\mathrm{A}, \mathrm{B}$, and $\mathrm{C}$, respectively. The photo of the rig configured for series $\mathrm{C}$ is prior to installation of the steel panels in order to show the vapor barrier location. 
The congestion inside the rig was provided by a regular array of vertical cylinders $(2.375$-inch and 2-inch outer diameter cylinders) giving area and volume blockage ratios (ABR and VBR) of 4.9\% and $2.2 \%$, respectively, within the congestion array. The 2.375 -inch outer diameter cylinders are located at the front of the rig in order to minimize plastic deformation resulting from repeated blast and drag loading. For test series $\mathrm{A}, \mathrm{B}$ and $\mathrm{C}$, the congestion extended throughout the entire enclosure. For test series D, the same congestion array was located in the center rear of the test rig (i.e., surrounding the location of ignition); however, it only extended over $25 \%$ of the enclosure. Figure 2 shows the congestion array for test series A, B, and C (top half of figure) and test series $\mathrm{D}$ (bottom half of figure). The obstacle-to-enclosure surface area ratio $\left(\mathrm{A}_{\mathrm{r}}\right)$ for the congestion array used in test series $\mathrm{A}$ was 0.3 . The congestion array $\mathrm{A}_{\mathrm{r}}$ for test series $\mathrm{B}$ and $\mathrm{C}$ was 0.33 , and test series $\mathrm{D}$ used a congestion array with an $\mathrm{A}_{\mathrm{r}}$ equal to 0.07 .

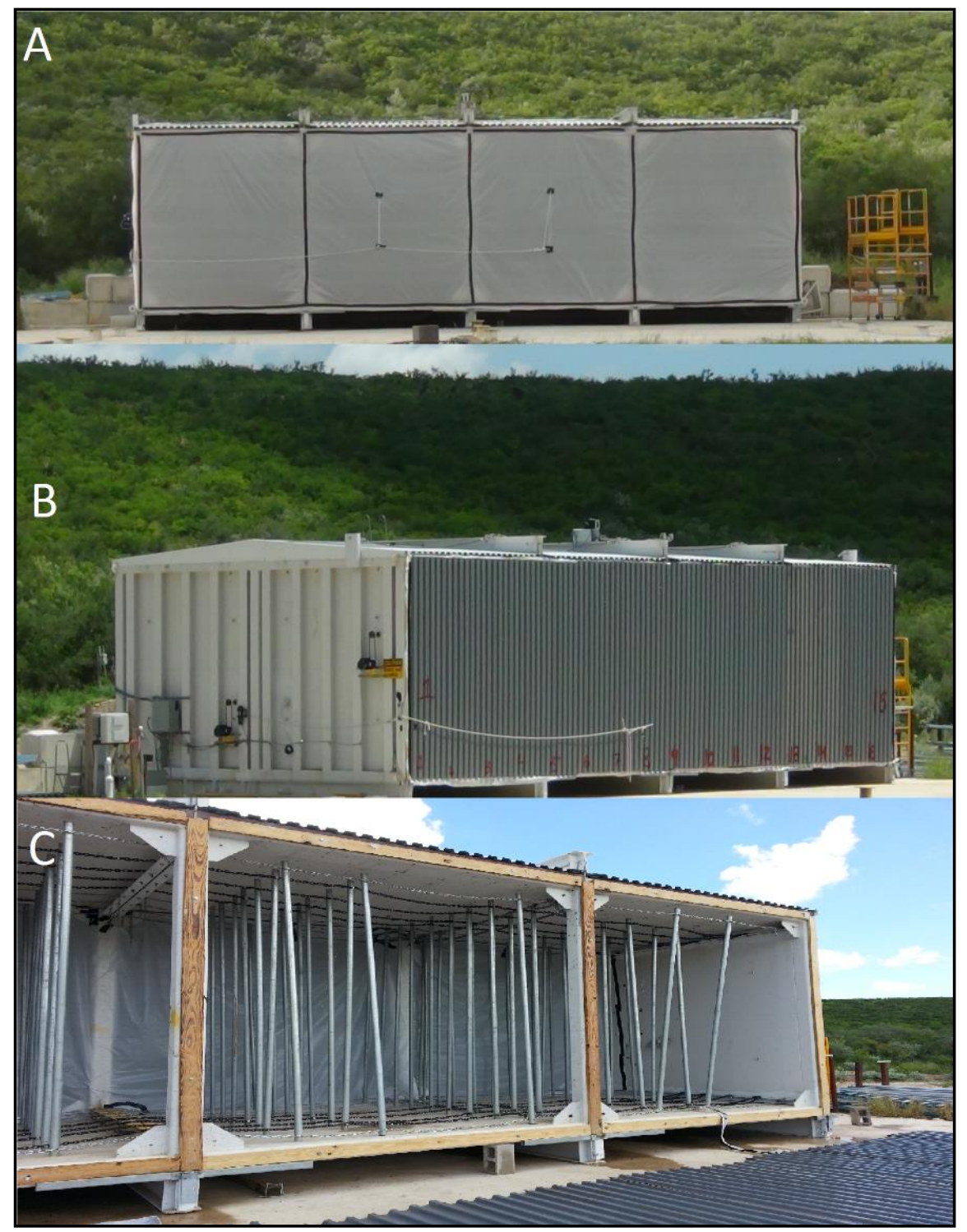

Figure 1: Test Rig Venting Configurations for Test Series A, B and C, respectively. 
Six pressure transducers were fielded within the test rig, and twenty-four transducers were fielded external to the rig directly in front of the venting surface. Internal to the rig, two transducers were located at the rear of the enclosure (east/west rear) at a height of 7 feet, two were located on the side walls (east/west wall) at a height of 4 feet, and two were located at grade level on the floor (east/west floor). External to the rig, three parallel transducer lanes were deployed, each containing eight transducers and aligned in the direction of blast wave propagation. High speed (3000 fps) and high definition (30 fps) cameras were deployed to record panel release. The layout of the interior and exterior pressure transducers and location of the video cameras is shown in Figure 3.

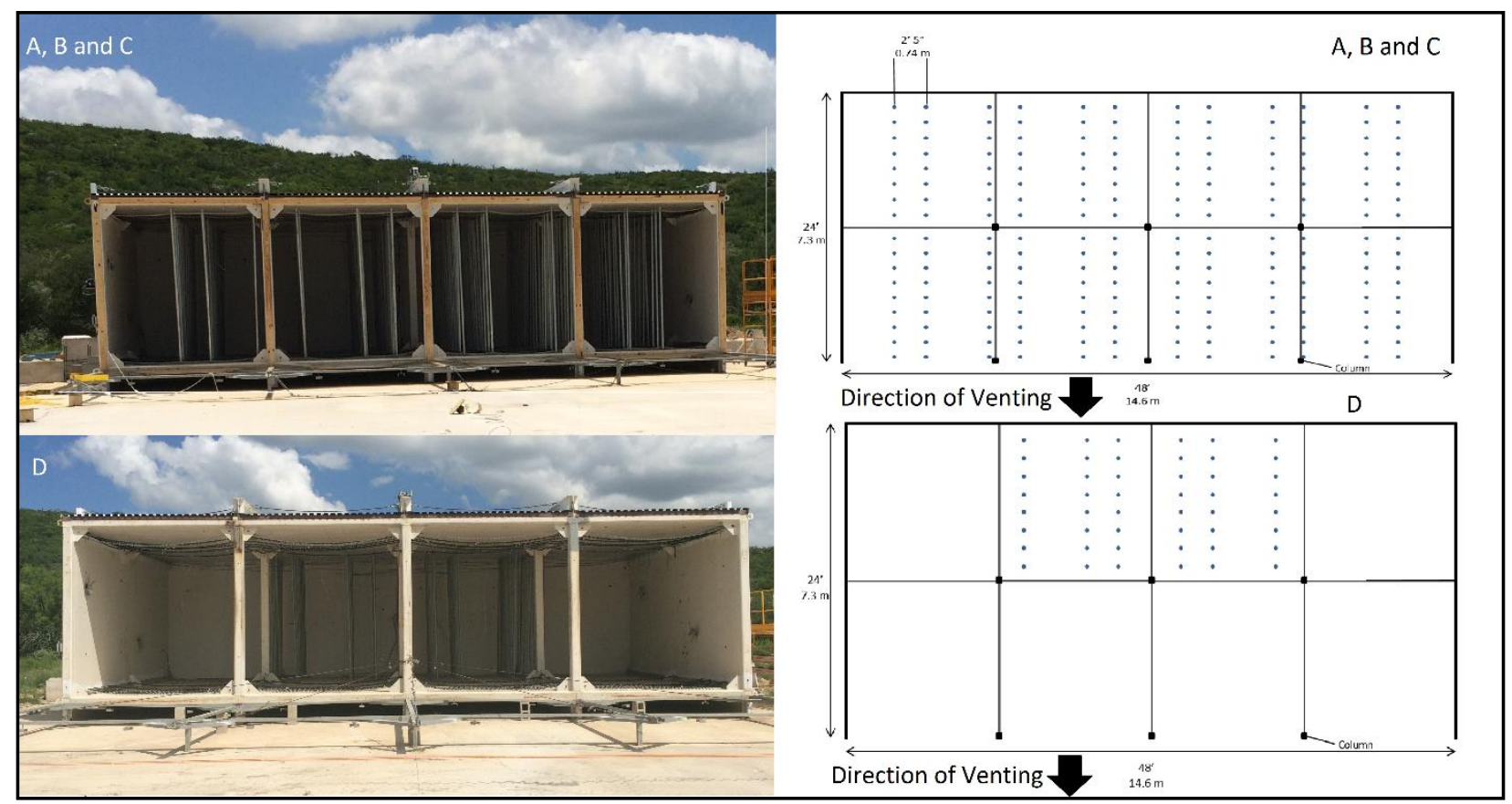

Figure 2: Test Rig Congestion Configuration for Test Series A, B, C and D. 


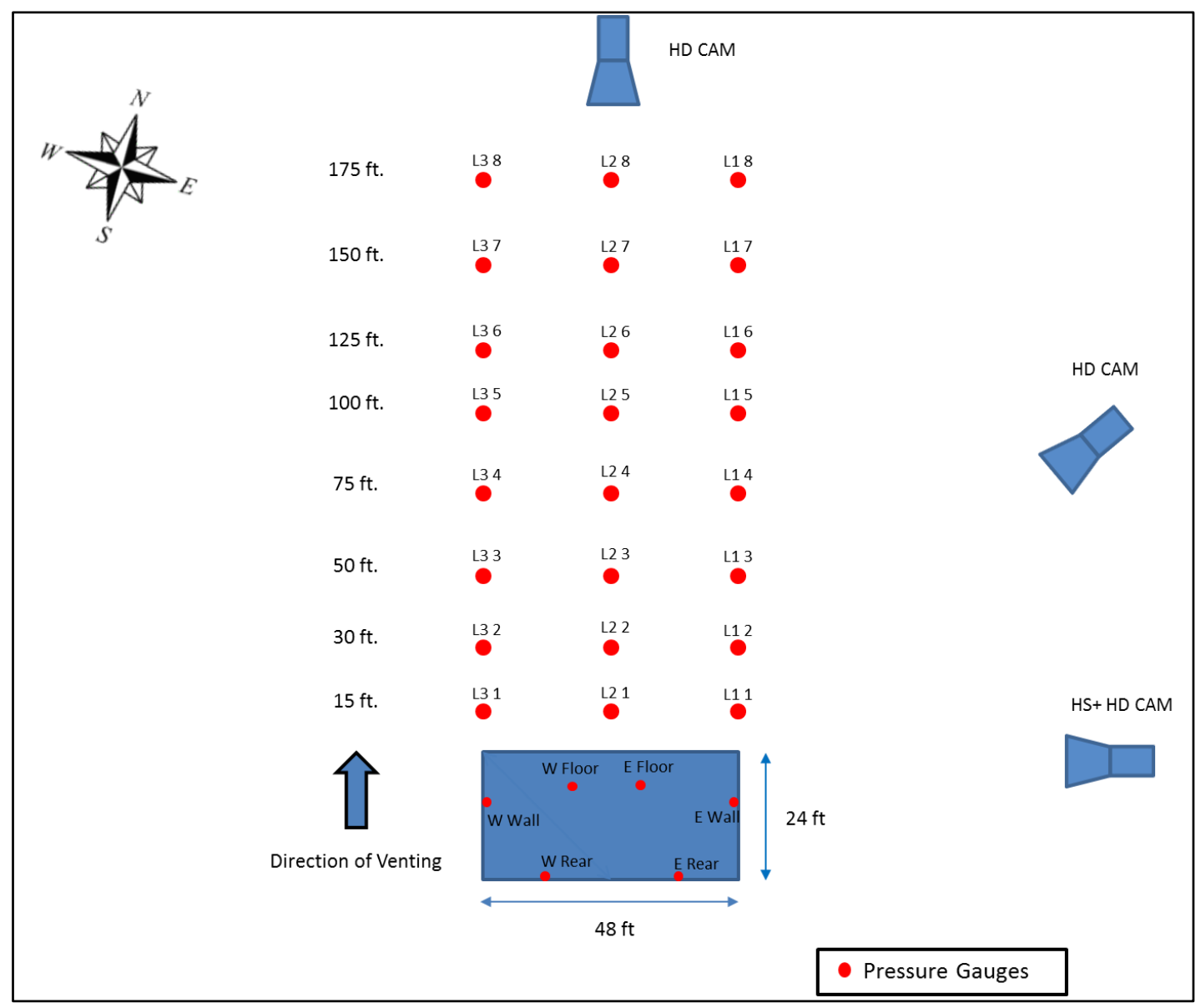

Figure 3: Pressure Transducer and Camera Layout

\section{Results and Discussion}

\section{$\underline{\text { Internal Pressure Measurements }}$}

Pressure measurements for the six internal pressure transducers were recorded for all tests. Exemplar pressure traces from test series B02 (fully congested / vent panels / 100\% flammable cloud volume) are provided in Figure 4. The peak pressures measured by the six internal transducers were used to determine an average internal peak pressure for each test, and subsequently for each test series. The maximum impulse (integration of pressure with respect to time) for each pressure transducer was calculated based on the positive phase of the measured pressure history. The average internal impulse was then determined for each test and series. The average internal peak pressure and impulse for the exemplar test shown in Figure 4 (B02) was 7.5 psig and 333 psi-ms, respectively, while the average internal peak pressure and impulse for the entire test series B (three tests total) was 7.0 psig and 320 psi-ms, respectively. The resulting average internal peak pressure and impulse are provided in Table 2. 


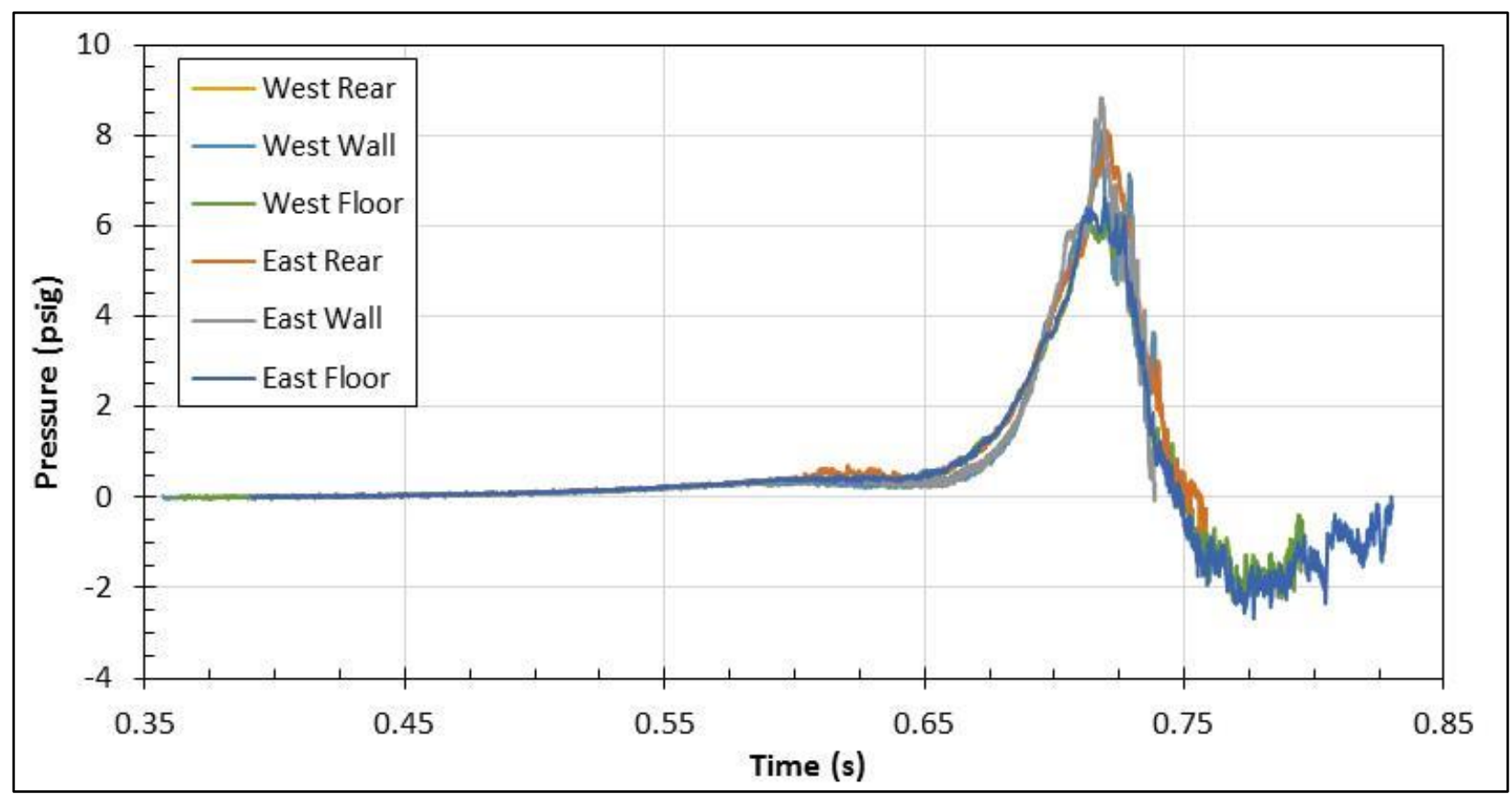

Figure 4: Pressure History inside the Test Rig for Test $\mathrm{B02}$

(Fully Congested, with Vent Panels and 100\% Flammable Cloud Volume)

Table 2. Series Average Peak Pressure, Impulse and Equivalent Duration

\begin{tabular}{|c|c|c|c|}
\hline \multirow{2}{*}{ Test Series } & \multicolumn{3}{|c|}{ Series Average Value } \\
\cline { 2 - 4 } & Peak Pressure (psig) & Impulse (psi-ms) & Equivalent Duration (ms) \\
\hline A & 5.3 & 230 & 87 \\
\hline B & 7.0 & 320 & 90 \\
\hline C & 6.6 & 300 & 91 \\
\hline D & 1.8 & 120 & 126 \\
\hline
\end{tabular}

Comparison to NFPA 68

The NFPA 68 correlation for venting deflagrations of gas mixtures was used to predict the internal peak pressure and duration for each test series. The internal peak pressure and duration were then used to determine the corresponding impulse. The average peak pressures internal to the test rig for all test series are shown in Figure 5 along with those predicted by NFPA 68. The internal impulse for each test series is shown in Figure 6, along with those based on NFPA 68. The peak pressures and impulses measured in these tests and based on NFPA 68 are also summarized in Table 3; the ratio of the measured value to that predicted by NFPA 68 is also provided.

Table 3. Measured and Predicted (NFPA 68) Blast Parameters

\begin{tabular}{|c|c|c|c|c|c|c|}
\hline \multirow{2}{*}{$\begin{array}{c}\text { Test } \\
\text { Series }\end{array}$} & \multicolumn{3}{|c|}{ Peak Pressure (psig) } & \multicolumn{3}{c|}{ Impulse (psi-ms) } \\
\cline { 2 - 7 } & Test & NFPA 68 & Ratio & Test & NFPA 68 & Ratio \\
\hline A & 5.3 & 2.7 & 2.0 & 230 & 277 & 0.8 \\
\hline
\end{tabular}




\begin{tabular}{|l|l|l|l|l|l|l|}
\hline $\mathrm{B}$ & 7.0 & 3.8 & 1.8 & 320 & 329 & 1.0 \\
\hline $\mathrm{C}$ & 6.6 & 2.8 & 2.4 & 300 & 248 & 1.2 \\
\hline $\mathrm{D}$ & 1.8 & 2.7 & 0.7 & 120 & 277 & 0.4 \\
\hline
\end{tabular}

The NFPA 68 vent area correlation accounts for congestion. However, the turbulence factor is constant (neglects varying levels of congestion) if the ratio of the obstacle surface area (Aobs) to that of the enclosure $\left(A_{s}\right)$ is less than 0.4 (i.e., $\left.A_{r}=A_{o b s} / A_{s}<0.4\right)$. The congestion array within the test rig resulted in an $A_{r}$ of less than 0.4 for all tests. The effect of congestion on peak pressure and impulse was therefore not explicitly accounted for in the NFPA 68 correlation predictions.

The ratios of the measured internal pressures to those predicted by NFPA 68 for test series A, B, and $\mathrm{C}$ are 2.0, 1.8, and 2.4, respectively. The average pressure for series $\mathrm{D}$ (25\% congestion) is in reasonable agreement with the NFPA 68 prediction, with the NFPA 68 internal pressure prediction being a factor of 1.4 larger than the measured value.

The calculated impulses based on NFPA 68 for series A and B agree well with the test data and are slightly conservative. The predicted impulse for series $\mathrm{C}$ is under-conservative by a factor of 0.8 compared to the test data. For series D, the impulse predicted by NFPA 68 is conservative by a factor of 2.3 compared to the test data. Given the reasonable level of agreement on impulse for series $\mathrm{A}, \mathrm{B}$, and $\mathrm{C}$, that the congestion level was reduced to $25 \%$ of that use for series $\mathrm{D}$, and that the NFPA 68 correlation does not account for changes in congestion level when $A_{r}<0.4$, it is to be expected that the predicted impulse for series $\mathrm{D}$ would not agree well with the test data.

In order for the NFPA 68 prediction to match the experimental pressure measured in test series B, the value of $A_{r}$ must be increased to about 0.95 , which corresponds to a congestion pattern with nearly three times as much piping as was actually present (i.e., a much higher congestion level). It is expected that if the congestion level in the test rig were actually increased to this level, the measured pressures would also be much higher. 


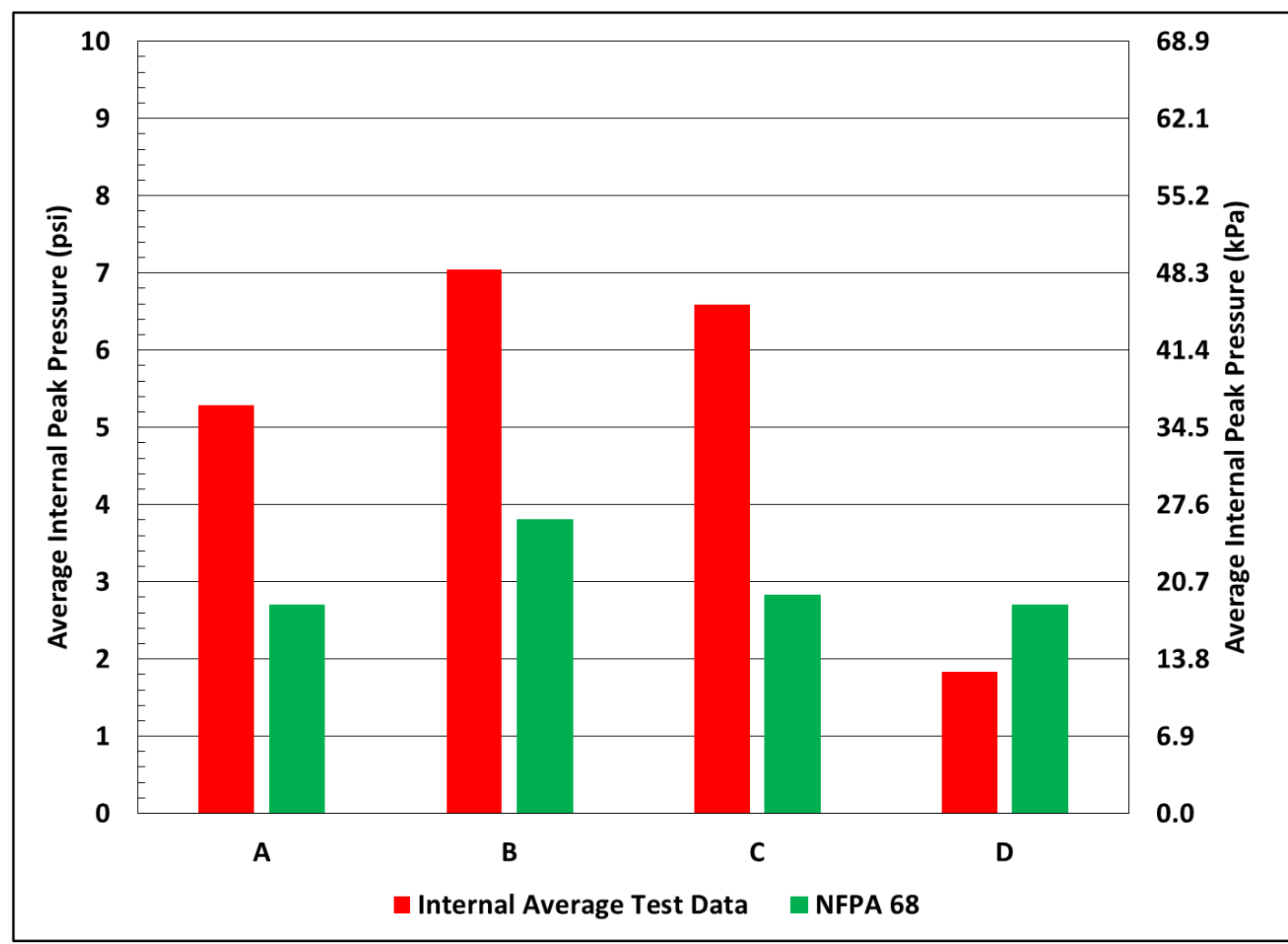

Figure 5: Average Internal Peak Pressure Compared to NFPA 68 [2013]

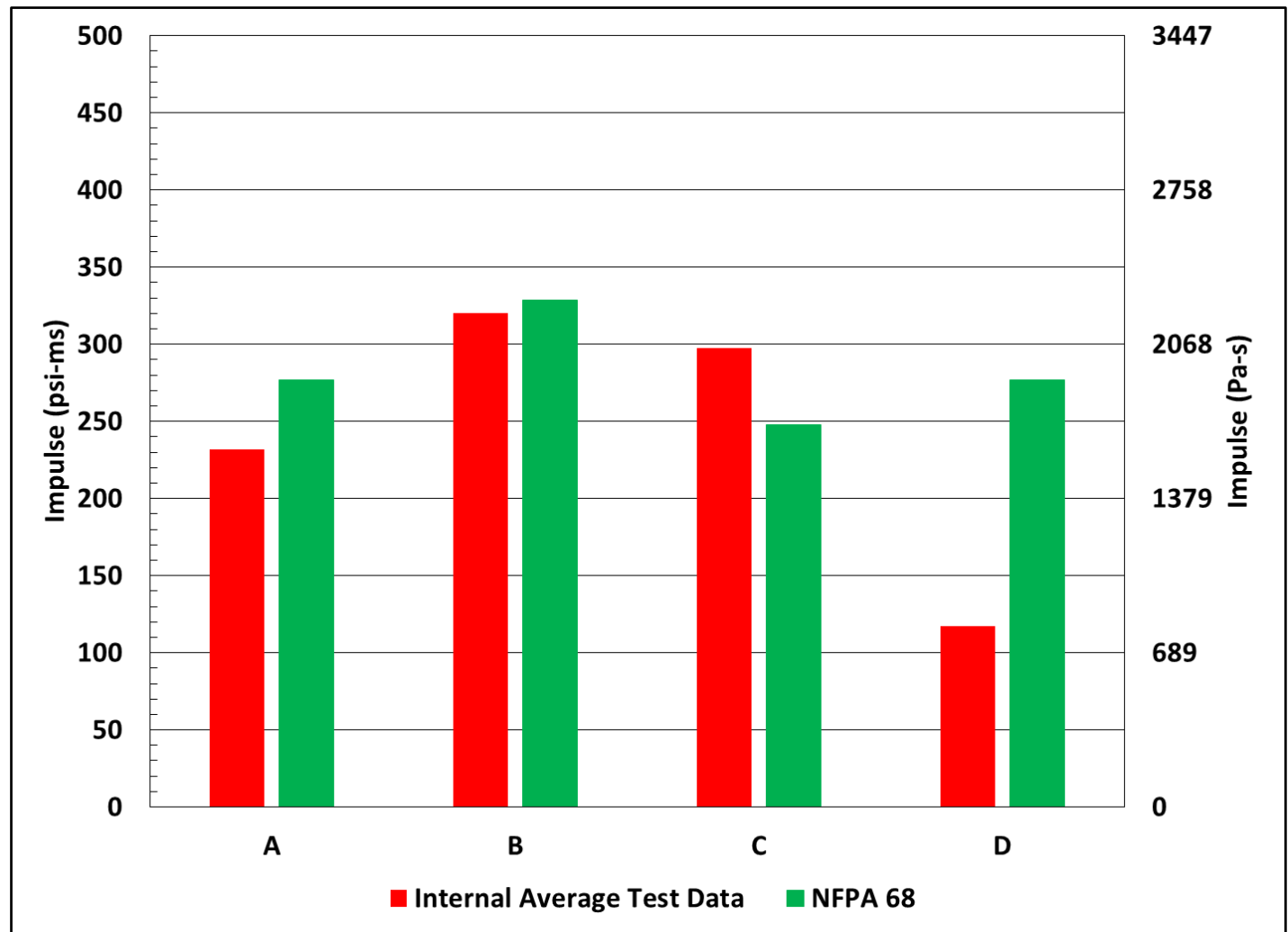

Figure 6: Average Internal Impulse Compared to NFPA 68 [2013] 


\section{External Pressure}

External pressure and impulse measurements were also recorded for all tests. Exemplar pressure traces from test series B02 (fully congested / vent panels / 100\% flammable cloud volume) are provided in Figure 7. The peak pressures from each of the three gauges located at a specific distance from the rig were averaged to provide the peak pressure at that distance for each test series. The average external impulse for each test series at each distance was calculated using the same averaging method as the average external peak pressure. The peak pressure and impulse for the exemplar test shown in Figure 7 (B02) at gauge L2 3 (see Figure 3 for gauge location reference), was 4.2 psig and 56 psi-ms, respectively, while the average peak pressure and impulse for the entire test series B at gauge L2-3, was 3.6 psig and 52 psi-ms, respectively. The average external pressure and impulse measurements from all test series are provided in Figure 8 and Figure 9, respectively. The trends in the resulting average external peak pressure and impulse data are discussed further in the following section.

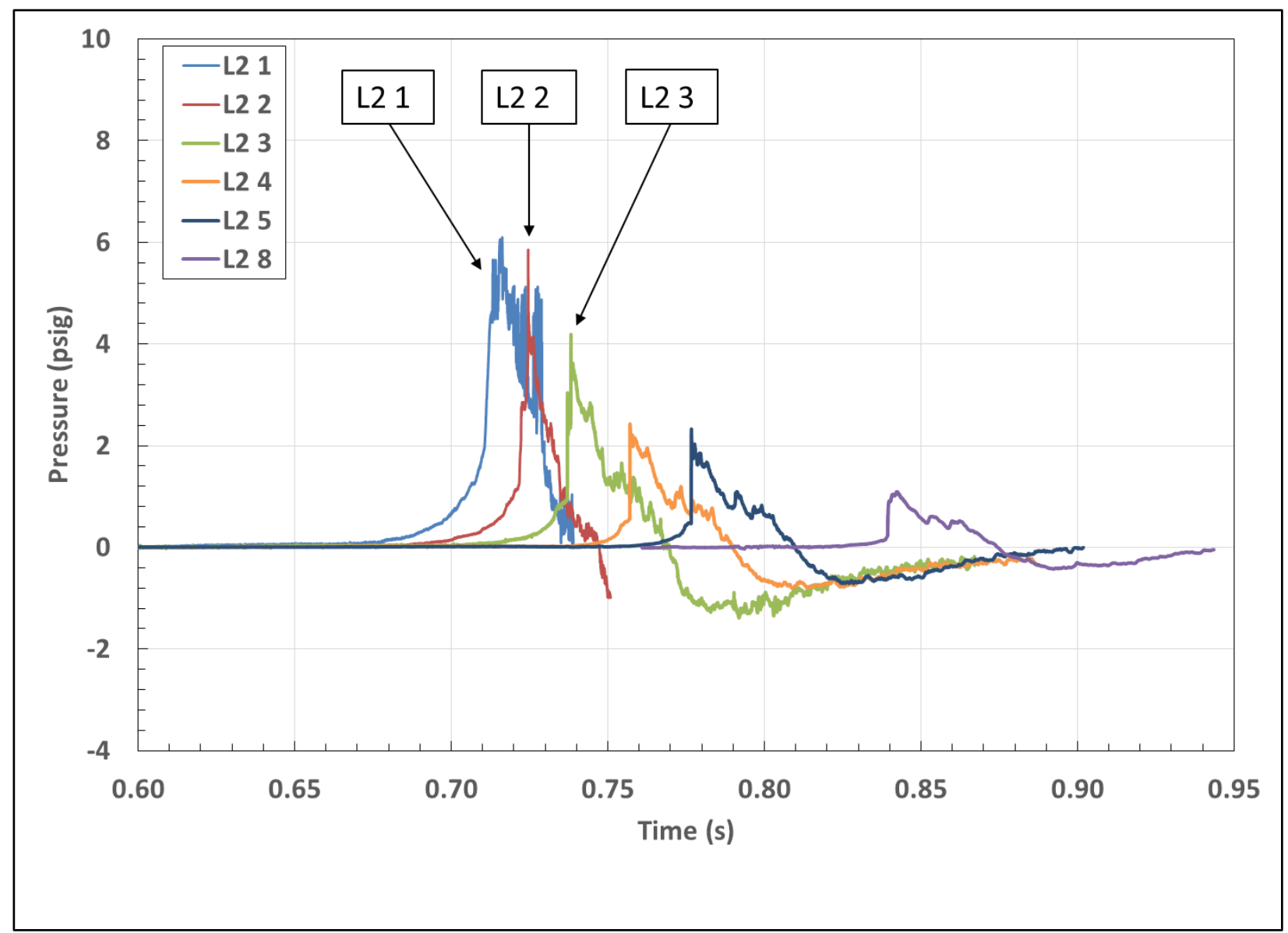

Figure 7: Pressure History External to the Test Rig for Test B02

(Fully Congested / Vent Panels / 100\% Flammable Cloud Volume) 


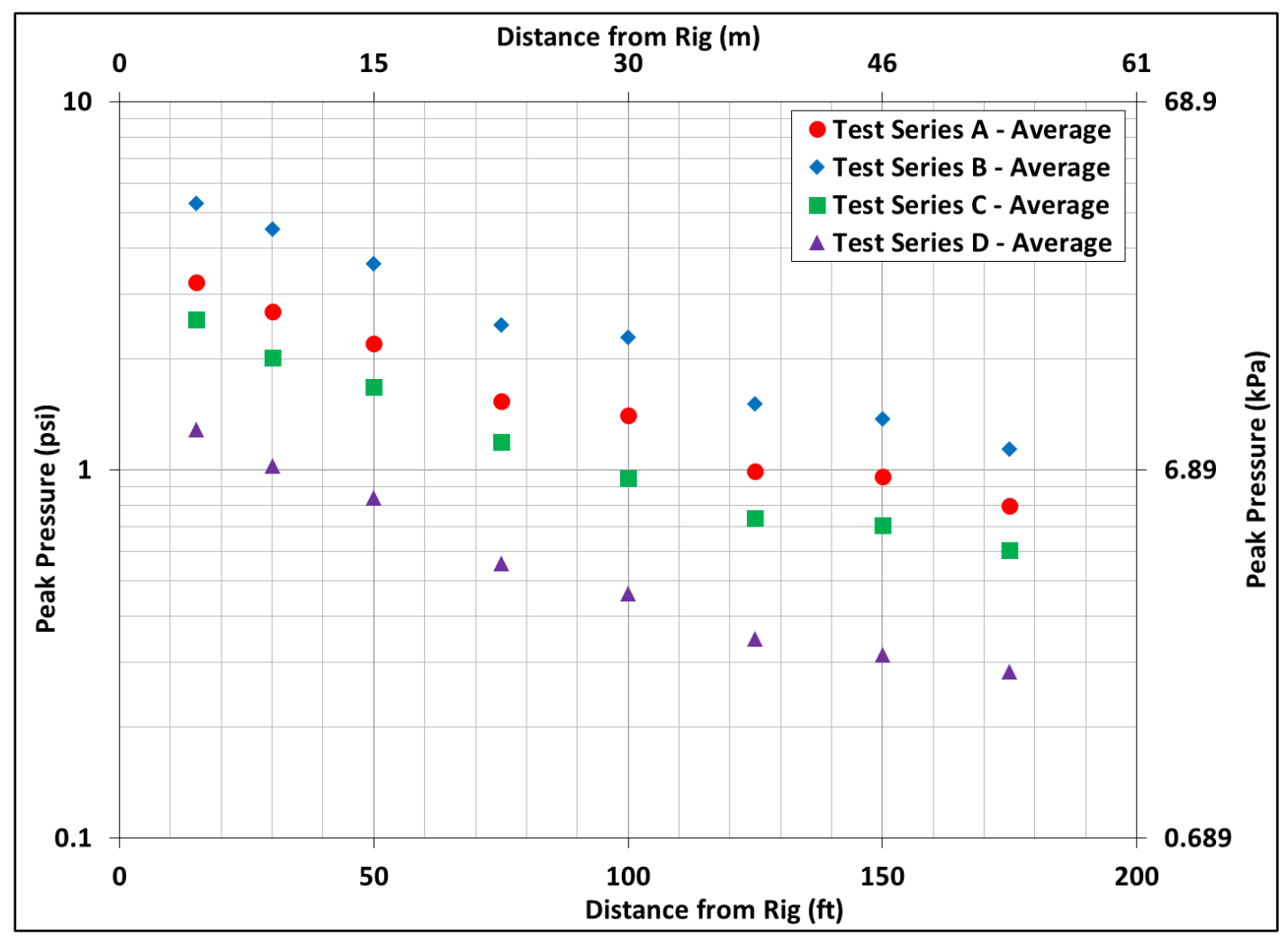

Figure 8: Average External Peak Pressure versus Distance from Rig

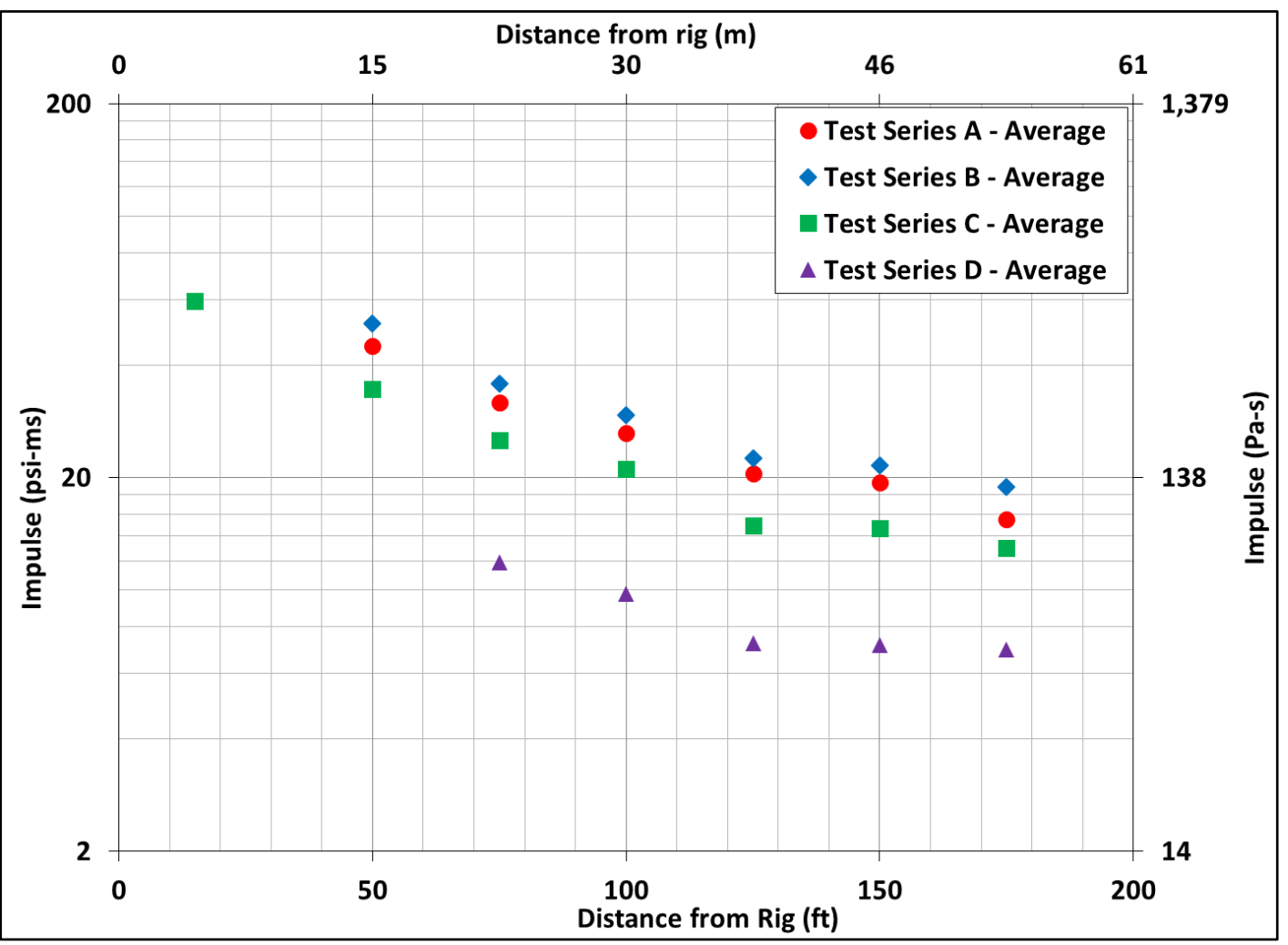

Figure 9: Average External Impulse versus Distance from Rig 


\section{Comparison of External Pressure Measurements}

The main parameters evaluated in this test program were flammable cloud volume and congested volume. In test series $\mathrm{C}$, the flammable cloud was reduced to $50 \%$ of that used in test series A and B (i.e., the entire rig volume). The total initial energy was therefore approximately $50 \%$ for test series $\mathrm{C}$ as compared to test series $\mathrm{A}$ and $\mathrm{B}$. The effect of the decreased initial flammable volume is apparent external to the rig; Figure 8 and Figure 9 show significantly decreased peak pressure and impulse measurements for test series $\mathrm{C}$ as compared to test series $\mathrm{B}$. These lower external blast loads are due to the lower total explosion energy (i.e., decreased flammable cloud volume).

The congested volume for test series D was reduced to $25 \%$ of that used in the other test series, for which the congested volume extended throughout the rig. The flame speed (energy release rate) is higher in the congested region relative to that in a non-congested region (i.e., reducing the congested volume reduces the overall energy release rate). The effect of reducing the congested volume is evident in the average external peak pressure and impulse, which were significantly reduced for series $\mathrm{D}$ as compared to series $\mathrm{A}, \mathrm{B}$, and $\mathrm{C}$.

\section{Panel Throw}

The throw distance of each panel was recorded. Figure 10 shows the maximum and average panel throw distances for each test in series $\mathrm{B}$ and $\mathrm{C}$ as a function of average internal peak pressure. Data from two tests conducted at fuel-lean conditions, which were not discussed in this paper, are also shown in Figure 10. The maximum and average panel throw distances were longer at an internal peak pressure of 4 psi as compared to an internal peak pressure 1 psi. The maximum and average panel throw distances for internal peak pressures between 4 psi and 8 psi were approximately constant. Panel throw distance at these higher pressures is related to the impulse imparted to the panel during the release process (i.e., vs. being a simple function of peak pressure). 


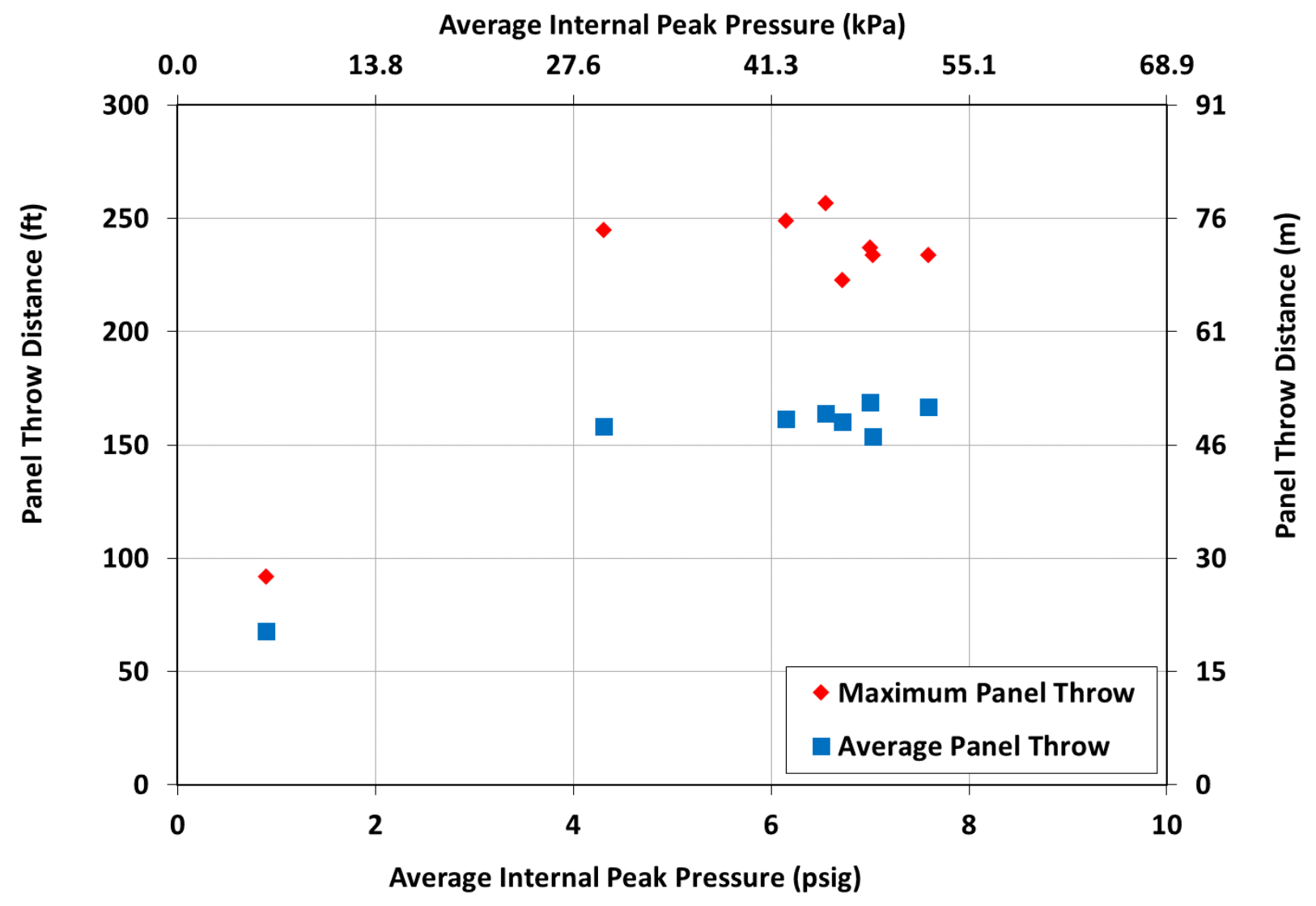

Figure 10: Panel Throw Distance versus Internal Peak Pressure

\section{Conclusions}

This test program was conducted to determine the peak deflagration pressure achieved within a congested enclosure vented through one wall, for a series of four test configurations (A through D). The internal peak pressures produced within a vented enclosure with a configuration similar to that used in test series A, B or C are higher than those predicted by NFPA 68 by a factor of approximately 2 . The rig configuration used in these tests provided a ratio of $\mathrm{Ar}_{\mathrm{r}}<0.4$. The congestion within the test rig was therefore not explicitly accounted for by the NFPA 68 peak internal pressure calculation (i.e., the turbulence factor is constant at this congestion level). When the congestion level was reduced by a factor of 4 in test series $\mathrm{D}$ resulting in as $\mathrm{A}_{\mathrm{r}} \sim 0.07$, reasonable agreement was found between the test data and the NFPA 68 correlation predictions, indicating that NFPA 68 is not conservative for a certain range of $A_{r}$ under conditions representative of these tests. For the NFPA 68 predictions to match the measured peak internal pressure for test series B, a congestion pattern of nearly 3 times as many pipes would be required, in which case it is expected the measured peak pressure would be much higher.

External peak pressure and impulse measurements were shown to significantly decrease when either the flammable cloud volume (inside the congested region) or the congested volume (inside the flammable cloud) were decreased, which is due to the decrease in total initial energy and overall energy release rate, respectively. The maximum and average panel throw distances for internal peak pressures between 4 psi and 8 psi were shown to be approximately constant. 


\section{Acknowledgments}

The test program described in this paper was performed under the sponsorship of the Explosion Research Cooperative (ERC), an ongoing joint industry research program organized by Baker Engineering and Risk Consultants, Inc. (BakerRisk ${ }^{\circledR}$ ). The ERC is comprised of companies, primarily engaged in the petrochemical and chemical industries, with a strong commitment to process safety. The ERC has continuously supported VCE testing and model development by BakerRisk since 1998 and the support of the ERC is gratefully acknowledged. The VCE tests described in this paper were carried out with the help and support of Darren Malik, Brad Horn, Emiliano Vivanco, Marty Goodrich, Randall Bloomquist, Hans Sunaryanto, Seth Johnson, Sean Howell, and Mattias Turner, and their contributions to this work are also acknowledged.

\section{References}

National Fire Protection Association, Standard on Explosion Protection by Deflagration Venting, NFPA 68 (2013 Edition), Quincy, MA. 